\title{
New CMA president decries waste, pushes prevention
}

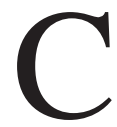
anada's health system needs better governance and accountability to eliminate waste, and doctors and patients need to pursue a healthy lifestyle to prevent disease, the new president of the Canadian Medical Association told colleagues in his inaugural address.

Dr. Louis Francescutti, an injury prevention and trauma specialist from Edmonton, Alberta, claims that a growing body of evidence suggests that eliminating three risk factors would prevent half the disease burden in Canada.

Smoking, inactivity and poor nutrition lead to certain cancers, diabetes, chronic respiratory disease and cardiovascular illness, Francescutti told about 300 delegates at the conclusion of the CMA's 146th annual General Council meeting in Calgary, Alta., on Aug. 21. That means doctors can play a prominent role in cutting health care costs just by asking their patients about those particular risks.

"Do you ask all your patients about these?" Francescutti asked. He also urged doctors and all Canadians to rely on so-called "super foods" including turkey, wild salmon, omega-3 eggs, berries, yogurts, spices, nuts and leafy greens - for optimal health.

The new president, who is an avid hockey fan and a stone mason in his free time, also identified three "sleeper" issues he encouraged doctors to advocate for: reducing fatigue, combating substance abuse and tackling mental illness.

"We really think that we can eliminate the majority of illness if we start thinking a lot differently," he said.

That shift includes learning more about how the social determinants of health lead to illness, Francescutti said. He urged his colleagues to educate themselves about how early childhood development and other consequences

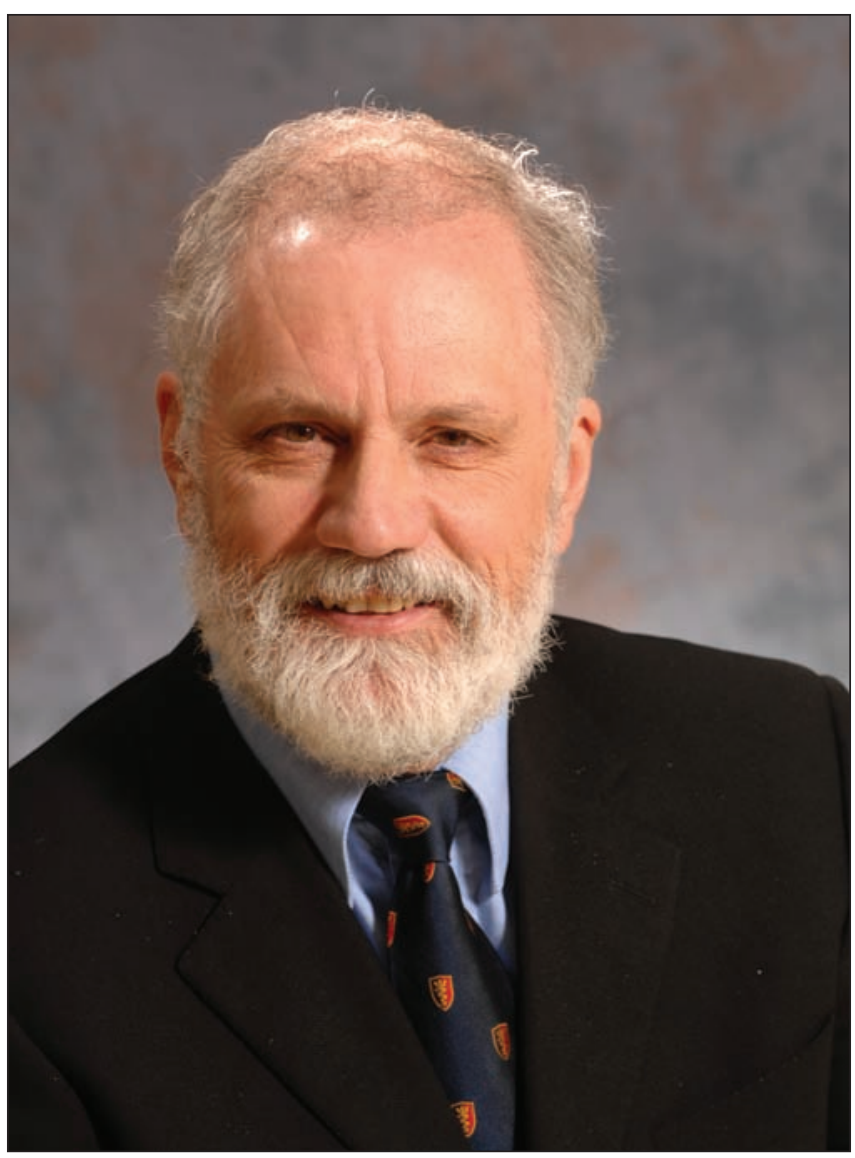

CMA's new president, Dr. Louis Francescutti is an injury prevention and trauma specialist from Edmonton, Alberta, and a former president of the Royal College of Physicians and Surgeons of Canada.

reduce unnecessary tests or on regulatory organizations to engage in better governance. Francescutti, a former president of the Royal College of Physicians and Surgeons of Canada, urged health organization staff to take corporate directors' courses and to avail themselves of Accreditation Canada's evaluation services. "If you don't have good governance within an institution, you're not going to get good output," he said.

Physicians also have to get better at evaluating not only what they do that doesn't work, but what they are not doing enough, as part of greater accountability, Francescutti said.

The new president wrapped up his address by referring to Health Minister Rona Ambrose's promise, delivered in her address earlier in the week, to work in partnership with the country's doctors on health care.

Many doctors at the meeting were hopeful that Ambrose's promise to consult the provinces and territories, and to discuss senior care, among other matters, indicates a shift in direction to more federal leadership on the health care file. But Francescutti also suggested

of living conditions affect individuals health. "If you don't spend [money] on early childhood development, you're going to spend it later in health, education and welfare and social services."

Advocating for spending to improve the social determinants of health, from housing and homelessness initiatives to poverty reduction, is a mantle outgoing President Dr. Anna Reid has passed on to Francescutti.

But he also pushed accountability, whether it be calling on doctors to that his political antennae are up.

"We heard some rather encouraging news from our new minister of health," he said. "The good news for us is it's early enough in the mandate that we can monitor if what we heard from the minister will translate into meaningful action. We are cautiously optimistic, but we know the feds have to get involved in this portfolio." - Laura Eggertson, CMAJ

CMAJ 2013. DOI:10.1503/cmaj.109-4589 